\title{
Age-dependent dichotomous effect of superoxide dismutase Ala16Val polymorphism on oxidized LDL levels
}

\author{
George V. Dedoussis ${ }^{1,3}$, Stavroula Kanoni ${ }^{1}$, \\ Demosthenes B. Panagiotakos ${ }^{1}$, Eirini Louizou', \\ Efi Grigoriou', Christina Chrysohoou', \\ Christos Pitsavos ${ }^{2}$ and Christodoulos Stefanadis ${ }^{2}$ \\ ${ }^{1}$ Department of Dietetics-Nutrition \\ Harokopio University, 70 El.Venizelou Avenue \\ 17671 Athens, Greece \\ ${ }^{2}$ First Cardiology Clinic \\ School of Medicine, University of Athens \\ Ippocration Hospital, 114 Vas Sofias Avenue, 11527 Athens, Greece \\ ${ }^{3}$ Corresponding author: Tel, 30-210-9549304; \\ Fax, 30-210-9577050; E-mail, dedousi@ hua.gr
}

Accepted 21 November 2007

Abbreviations: BMI, body mass index; $\mathrm{Cu} / \mathrm{Zn} \mathrm{SOD}$, copper- and zinc containing superoxide dismutase; GPX, glutathione peroxidase; $\mathrm{Mn}$ SOD, manganese superoxide dismutase; RNS, reactive nitrogen species; ROS, reactive oxygen species; SOD, superoxide dismutase

\begin{abstract}
We investigated the association between superoxide dismutase (SOD) Ala16Val polymorphism and the levels of oxidized LDL lipoprotein-C (ox-LDL-C) in two age-different Greek cohorts. Four hundred fifteen middle-aged ( $n=147$ females: $43.2 \pm 13$ years, $n=268$ males: $\mathbf{4 3 . 3} \pm 14$ years) Caucasian Greek subjects consisted the middle aged cohort. One hundred seventy five elderly ( $n=88$ females: $79.9 \pm 4$ years; $n=87$ males: $80.6 \pm 4$ years) were selected from the elderly cohort. Genotype data were obtained for all of them. Multiple linear regression analysis, stratified by gender and adjusted for age, smoking habits and body mass index as covariates, showed higher ox-LDL-C levels for the middle aged men with the Val/Val genotype, compared to the other allele (Ala/Ala and Ala/Val) carriers $(65.9 \pm 25.7$ vs. $55.7 \pm 20.5 \mathrm{mg} / \mathrm{dl}$; standardized $\beta$ coefficient $=0.192, P=0.012$ ). On the contrary, elderly women with the Val/Val genotype occurred with lower ox-LDL-C levels compared to the Ala/Ala or Ala/Val genotype (74.2 \pm 22.1 vs. $86.5 \pm$ $26.6 \mathrm{mg} / \mathrm{dl}$; standardized $\beta$ coefficient $=-0.269, P=$ $0.015)$. The same trend was also recorded in elderly men, however without reaching statistical signifi-
\end{abstract}

cance (standardized $\beta$ coefficient $=-0.187, P=0.077$ ). Moreover, elderly men and women with the Ala/Ala or Ala/Val genotype presented higher triglycerides levels compared to Val/Val (women: $145.2 \pm 68.7$ vs. 114.3 $\pm 34.3 \mathrm{mg} / \mathrm{dl}, P=0.027$; men: $147.8 \pm 72.4$ vs. 103.7 $\pm 38.0 \mathrm{mg} / \mathrm{dl}, P=0.002$ ). Additionally, middle aged men with the Val/Val genotype had higher HDL-C levels compared to the Ala allele carriers. The results suggest that SOD Ala16Val polymorphism is an age-dependent modulator of ox-LDL-C levels in middle-aged men and elderly women.

Keywords: aging; aged, 80 and over; oxidized low density lipoprotein; polymorphism, genetic; superoxide dismutase

\section{Introduction}

Aging is an inevitable, heterogeneous but inducible process, characterized by a general decline in physiologic function with an increasing morbidity and mortality rate. Specific causes of aging are not completely elucidated, although various lines of evidence implicate random (stochastic) events as a fundamental driving force behind this process. The free radical theory of aging was postulated as early as 1956 by Harman (1956) and it may explain many of the physiologic changes associated with aging. According to this hypothesis, different types of free radicals are formed in aerobic organisms, particularly due to their metabolic activity. The most important free radicals are the reactive oxygen species (ROS), which have been shown to damage a whole spectrum of cellular key components, during the aging process (Gutteridge and Halliwell, 2000). Free radicals and reactive oxygen and nitrogen species (ROS, RNS) are mutagenic compounds, known to cause DNA damage, favor cell transformation, and contribute to the development of a variety of malignant diseases.

Atherosclerosis is one of the major health concerns in developed countries. It is also well-known, that atherosclerosis is closely related to lipoprotein metabolism. In particular, oxidative modification of LDL is involved in the early development of atherosclerotic lesions, through the formation of macrophage-derived foam cells. Subsequently, ROS formation and oxidative stress contribute to the atherogenetic process (Rosenblat et al., 2002). 
Several studies have demonstrated the presence of lipid peroxides and byproducts of lipid peroxidation in LDL-C particles and in arterial macrophages in atherosclerotic lesions (Mertens and Holvoet, 2001; Rosenblat et al., 2002). Similarly, it is assumed that lipid peroxidation, subsequent to free-radical damage, is involved in the aging process (Schwenke, 1998).

Several enzymes with antioxidant activity [superoxide dismutase (SOD), glutathione peroxidase (GPX), catalase] comprise a fundamental system, developed by aerobic organisms, to prevent oxidative damage. SODs are the only enzymes dismounting superoxide radicals. There are numerous mechanisms by which cells defend themselves against oxidants (Kinnula and Crapo, 2004). SODs decompose superoxide radicals into $\mathrm{H}_{2} \mathrm{O}_{2}$ and $\mathrm{O}_{2}$ (Kinnula and Crapo, 2004). Mammalian cells, in particular, contain a manganese superoxide dismutase (Mn SOD/SOD2) localized within the mitochondrial matrix (Weisiger and Fridovich, 1973), a copper- and zinc-containing superoxide dismutase (Cu/Zn SOD/SOD1) localized predominantly in cytoplasmic and nuclear compartments (McCord and Fridovich, 1969), and a copper- and zinc containing SOD predominantly found in extracellular compartments (EC SOD/SOD3) (Marklund, 1982). MnSOD, a homotetramer containing one manganese ion per subunit (Beyer et al., 1991; Wan et al., 1994), is essential for the vitality of mammalian cells. The MnSOD gene is located on chromosome 6q25 (Wan et al., 1994). Total knockout of the MnSOD gene is perinatally lethal, leading to neurological manifestations and cardiotoxicity (Tsan, 2001; Van Remmen et al., 2001). Heterozygous mice with decreased MnSOD activity present increased mitochondrial oxidative damage (Williams et al., 1998). A polymorphic variant of MnSOD, with possible enhancing effect on the risk of cancer development, has been described. In this variant, a substitution of $T$ to $C$ base results in the replacement of alanine (Ala) with valine (Val) at position 16 of the mitochondrial targeting sequence (16th amino acid from the beginning of the signal sequence or 9th amino acid from the first amino acid of the mature protein) (Rosenblum et al., 1996). This amino acid replacement has been suggested to change the mitochondrial targeting of the enzyme. It has recently been shown, that the Ala MnSOD/mitochondrial targeting sequence allows efficient targeting of MnSOD to the mitochondria, whereas the Val variant leads to a decreased formation of active MnSOD in the mitochondrial matrix (Sutton et al., 2003).

To examine the influence of the SOD Ala16Val polymorphism on the levels of oxidized low-density lipoprotein (ox-LDL) during the ageing process, we studied two age different Greek cohorts.

\section{Materials and Methods}

The gene symbols used in this article follow the recommendations of the HUGO Gene Nomenclature Committee (Povey et al., 2001).

\section{Healthy adults and very old people}

Middle aged cohort: The middle aged cohort included 415 middle-aged subjects. This group was part of the "ATTICA" study (Pitsavos et al., 2003), which is a health and nutrition survey, carried out in the province of Attica (including 78\% urban and $22 \%$ rural areas), where Athens, is a major metropolis. The sampling was performed in the working or other public places; it was random, multistage and based on the age-sex distribution of the province of Attica provided by the National Statistical Service (census of 2001). The participation rate was $68 \%$. From the sampling we excluded $10 \%$ of men and $7 \%$ of women with history of chronic disease (renal failure, liver and cardiovascular disease and chronic obstructive pulmonary disease), as well as individuals $(<2 \%)$ who were under current or chronic use of certain drugs that influence antioxidant status, like methotrexate, trimethoprin, cholestyramine and cyclosporine. Also, all people living in institutions were excluded from the study. All participants were interviewed by trained personnel (cardiologists, dieticians and nurses), using a standard questionnaire.

Elderly cohort: The elderly subjects included in the present study, were part of a large elderly cohort called GHRAS (Greek Health Randomized Aging Study), consisting of 800 healthy men and women older than 65 years of age (unpublished data). The elderly cohort selected for the present study is a sample of 175 subjects older than 75 years of age. The selection criteria was the equal representation all the Ala16Val SOD genotypes in both genders of elderly subjects. Furthermore, the oldest participants had to be free of medication such as antilipidemics, anticoagulants, steroids, diuretics, anticonvulsants, anti-depressive drugs, antibiotics, antimetabolites, non-steroid anti-inflammatory drugs and micronutrient supplementation. Subjects were excluded if they had autoimmune, neurodegenerative, cardiovascular, kidney or liver disease, diabetes, infections, cancer, chronic inflammatory bowel disease or acrodermatitis enteropathica, sickle cell anaemia, chronic skin ulcerations and endocrine disorders. Medical history was recorded by the family doctor or 
through a medical examination when possible.

\section{Genotyping}

Genomic DNA was extracted from whole blood leukocytes with a DNA extraction kit (Nucleospin Blood kit, Macherey-Nagel, Düren, Germany). Ala16Val SOD genotype was determined, as previously described (Masry et al., 2005), for 415 subjects of the middle aged cohort and 212 of the elderly cohort.

\section{Biochemical analysis}

Blood samples were collected after $12 \mathrm{~h}$ fasting. The biochemical analysis included total cholesterol, HDL-C, triglycerides and glucose measurements. LDL-C was calculated using the Friedewald equation. Ox-LDL-C was measured in plasma samples using a commercial ELISA kit (Mercodia $A B$, Uppsala, Sweden), following the manufacturer's instructions.

\section{Anthropometric, clinical, demographic and lifestyle characteristics}

The anthropometric measurements included weight and height and were obtained using standardized techniques and equipment. Body mass index (BMI) was calculated as weight $(\mathrm{kg}) /$ height $(\mathrm{m})$ squared. Arterial blood pressure was measured 3 times on the right arm with a sphygmomanometer and with the subject in a sitting position for $30 \mathrm{~min}$. Demographic (age and gender) and lifestyle characteristics (smoking habits) of the middle-aged and the elderly participants were recorded using standardised questionnaires. Current smokers were defined as those who smoked at least one cigarette per day.

\section{Statistical analysis}

Continuous variables are presented as mean \pm standard deviation, while categorical variables are presented as absolute and relative frequencies. Pearson's correlation coefficient was used in order to measure associations between normally distributed continuous variables. Contingency tables with the calculation of chi-squared test (with Yates correction) evaluated the associations between categorical variables. However, due to the small number of observations in some cases, Fisher's exact test, with the calculation of exact $P$-values, was applied to evaluate the association between the investigated polymorphism and group of study. The application of Student's $t$-test evaluated the associations between categorical and normally distributed continuous variables. The distribution of the SOD polymorphism in both populations was compared with the expected frequency through the Hardy-Weinberg equilibrium (HWE). Testing deviations from the HWE was performed by Pearson's chi-squared test, using the observed genotype frequencies obtained from the data and the expected genotype frequencies obtained using the HWE. The association of genotypes with ox-LDL-C concentrations were tested by using multiple linear regression models, after taking into account the effects of several potential confounders. All reported $P$ values are based on two- sided tests and were compared with a significance level of $5 \%$. Statistical analysis was performed with SPSS edition 13.0.

\section{Results}

We evaluated the prevalence of the SOD Ala16Val polymorphism and its effect on ox-LDL-C levels in two age different Greek cohorts, a middle aged one ( $n=147$ females: $43.2 \pm 13$ years, $n=268$ males: $43.3 \pm 14$ years) and an oldest old cohort (females: $79.9 \pm 4$ years; males: $80.6 \pm 4$ years). The allele frequency observed in both populations of the current study was 0.54 for Ala and 0.46 for Val. Genotypes frequency was in HWE. Table 1 presents anthropometrical, clinical and biochemical variables of the two cohorts, according to the SOD Ala16Val genotype. Middle aged men with the $\mathrm{Val} /$ Val genotype had higher ox-LDL-C and HDL-C levels compared to the Ala carriers (Ala/Ala or Ala/Val) $(65.9 \pm 25.7$ vs. $55.7 \pm 20.5 \mathrm{mg} / \mathrm{dl}, P=$ 0.011 for the ox-LDL-C; $47.4 \pm 12.7$ vs. $43.5 \pm$ $10, P=0.020$ for the HDL- C). Furthermore, middle aged men with the $\mathrm{Val} / \mathrm{Val}$ genotype had lower total cholesterol/ox-LDL ratio compared to the Ala carriers (Table 1). On the contrary, elderly women with the Ala/Ala or Ala/Val genotype presented higher ox-LDL-C levels and lower total cholesterol/ ox-LDL ratio compared to the $\mathrm{Val} / \mathrm{Val}$ genotype $(86.5 \pm 26.6$ vs. $74.2 \pm 22.1 \mathrm{mg} / \mathrm{dl}, P=0.042$ for the ox-LDL; $2.9 \pm 0.7$ vs. $3.2 \pm 0.8, P=0.029$ for the total cholesterol/ox-LDL ratio). Both elderly men and women with the Ala/Ala or Ala/Val genotype occurred with higher triglycerides levels compared to the Val/Val group (147.8 \pm 72.4 vs. 103.7 $\pm 38.0 \mathrm{mg} / \mathrm{dl}, P=0.002$ and $145.2 \pm 68.7 \mathrm{vs}$. $114.3 \pm 34.3 \mathrm{mg} / \mathrm{dl}, P=0.027$, for men and women respectively). Multiple linear regression analysis (Table 2), stratified by gender and adjusted for age, body mass index and smoking habits as covariates, confirmed the dichotomous age effect of the 
Table 1. Characteristics of the participants by genotype for the Ala16Val mutation of the SOD gene.

\begin{tabular}{|c|c|c|c|c|c|c|}
\hline \multirow{2}{*}{ Middle aged cohort } & \multicolumn{3}{|c|}{ Women } & \multicolumn{3}{|c|}{ Men } \\
\hline & Ala/Ala, Ala/Val & Val/Nal & $P$ & Ala/Ala, Ala/Val & Val/Nal & $P$ \\
\hline$n$ & 124 & 23 & & 216 & 52 & \\
\hline Age (y) & $38.9 \pm 11.5$ & $38.7 \pm 11.3$ & 0.924 & $45.7 \pm 9.8$ & $46.0 \pm 9.2$ & 0.834 \\
\hline BMl $\left(\mathrm{kg} / \mathrm{m}^{2}\right)$ & $23.8 \pm 4.4$ & $25.7 \pm 5.7$ & 0.075 & $27.8 \pm 4.1$ & $27.3 \pm 3.4$ & 0.409 \\
\hline Systolic Blood Pressure (mmHg) & $113.6 \pm 16.4$ & $113.3 \pm 15.7$ & 0.932 & $127.9 \pm 17.3$ & $128.7 \pm 19.0$ & 0.772 \\
\hline Diastolic Blood Pressure (mmHg) & $76.7 \pm 14.0$ & $78.0 \pm 13.6$ & 0.661 & $84.7 \pm 15.8$ & $97.0 \pm 94.8$ & 0.365 \\
\hline Total Cholesterol (mg/dl) & $179.6 \pm 39.3$ & $184.1 \pm 37.5$ & 0.612 & $197.4 \pm 33.7$ & $195.7 \pm 36.6$ & 0.749 \\
\hline HDL-C (mg/dl) & $52.6 \pm 10.9$ & $51.3 \pm 12.5$ & 0.619 & $43.5 \pm 10.0$ & $47.4 \pm 12.7$ & 0.020 \\
\hline LDL-C (mg/dl) & $110.4 \pm 35.3$ & $108.6 \pm 35.8$ & 0.828 & $127.5 \pm 31.4$ & $122.6 \pm 34.1$ & 0.329 \\
\hline Triglycerides (mg/dl) & $84.6 \pm 44.9$ & $120.9 \pm 111.0$ & 0.136 & $130.2 \pm 74.3$ & $130.4 \pm 61.8$ & 0.986 \\
\hline Oxidized LDL-C (U/L) & $61.3 \pm 32.3$ & $65.9 \pm 29.0$ & 0.532 & $55.7 \pm 20.5$ & $65.9 \pm 25.7$ & 0.011 \\
\hline Total Cholesterol/Oxidized LDL-C & $3.7 \pm 2.2$ & $3.3 \pm 1.3$ & 0.207 & $4.0 \pm 1.4$ & $3.4 \pm 1.5$ & 0.029 \\
\hline Glucose (mg/dl) & $87.2 \pm 11.3$ & $101.2 \pm 57.8$ & 0.260 & $97.0 \pm 24.1$ & $104.3 \pm 35.9$ & 0.169 \\
\hline Current smokers (\%) & 42.0 & 39.0 & 0.800 & 48 & 46 & 0.790 \\
\hline \multirow{2}{*}{ Elderly cohort } & \multicolumn{3}{|c|}{ Women } & \multicolumn{3}{|c|}{ Men } \\
\hline & Ala/Ala, Ala/Val & Val/Nal & $P$ & Ala/Ala, Ala/Val & Val/Nal & $P$ \\
\hline $\bar{n}$ & 62 & 26 & & 65 & 22 & \\
\hline Age $(y)$ & $80.5 \pm 4.4$ & $78.3 \pm 3.5$ & 0.023 & $80.7 \pm 4.3$ & $80.3 \pm 5.3$ & 0.750 \\
\hline BMl $\left(\mathrm{kg} / \mathrm{m}^{2}\right)$ & $29.3 \pm 4.3$ & $30.1 \pm 4.6$ & 0.454 & $28.1 \pm 3.6$ & $28.7 \pm 4.0$ & 0.553 \\
\hline Systolic Blood Pressure (mmHg) & $147.0 \pm 21.4$ & $139.2 \pm 20.9$ & 0.147 & $150.6 \pm 17.1$ & $143.6 \pm 18.0$ & 0.128 \\
\hline Diastolic Blood Pressure (mmHg) & $76.7 \pm 10.8$ & $79.1 \pm 12.0$ & 0.384 & $79.1 \pm 10.7$ & $77.5 \pm 12.5$ & 0.585 \\
\hline Total Cholesterol (mg/dl) & $235.1 \pm 34.5$ & $226.5 \pm 40.8$ & 0.321 & $227.4 \pm 36.4$ & $210.8 \pm 45.8$ & 0.087 \\
\hline HDL-C (mg/dl) & $55.5 \pm 12.4$ & $60.1 \pm 12.3$ & 0.112 & $52.3 \pm 10.7$ & $51.1 \pm 9.0$ & 0.646 \\
\hline LDL-C (mg/dl) & $150.6 \pm 32.5$ & $143.5 \pm 39.2$ & 0.389 & $145.5 \pm 32.4$ & $138.9 \pm 38.9$ & 0.434 \\
\hline Triglycerides (mg/dl) & $145.2 \pm 68.7$ & $114.3 \pm 34.3$ & 0.027 & $147.8 \pm 72.4$ & $103.7 \pm 38.0$ & 0.002 \\
\hline Oxidized LDL-C (U/L) & $86.5 \pm 26.6$ & $74.2 \pm 22.1$ & 0.042 & $81.3 \pm 21.8$ & $73.1 \pm 19.1$ & 0.119 \\
\hline Total Cholesterol/Oxidized LDL-C & $2.9 \pm 0.7$ & $3.2 \pm 0.8$ & 0.029 & $2.9 \pm 0.7$ & $3.0 \pm 0.5$ & 0.817 \\
\hline Glucose (mg/dl) & $104.2 \pm 29.0$ & $95.0 \pm 12.9$ & 0.127 & $110.2 \pm 33.6$ & $102.0 \pm 20.7$ & 0.288 \\
\hline Current smokers (\%) & 8.1 & 11.5 & 0.689 & 15.4 & 4.5 & 0.277 \\
\hline
\end{tabular}

Table 2. Results from multiple linear regression models that evaluated the association between oxidized LDL-C concentrations and SOD genotype stratified by gender*.

\begin{tabular}{|c|c|c|c|c|}
\hline Middle-aged cohort & \multicolumn{2}{|l|}{ Women } & \multicolumn{2}{|l|}{ Men } \\
\hline Variable & Standardized $\beta$ coefficient & $P$ & Standardized $\beta$ coefficient & $P$ \\
\hline Val/Nal vs. Ala/Ala, Ala/Val & 0.071 & 0.410 & 0.192 & 0.012 \\
\hline Age $(y)$ & -0.045 & 0.640 & 0.100 & 0.195 \\
\hline $\mathrm{BMI}\left(\mathrm{kg} / \mathrm{m}^{2}\right)$ & -0.094 & 0.341 & -0.137 & 0.076 \\
\hline Non-smoking vs. current smoking & 0.071 & 0.175 & 0.016 & 0.832 \\
\hline Adjusted $\mathrm{R}^{2}$ & $0.3 \%$ & 0.361 & $4.2 \%$ & 0.025 \\
\hline Elderly cohort & \multicolumn{2}{|l|}{ Women } & \multicolumn{2}{|l|}{ Men } \\
\hline Variable & Standardized $\beta$ coefficient & $P$ & Standardized $\beta$ coefficient & $P$ \\
\hline Val/Val vs. Ala/Ala, Ala/Val & -0.269 & 0.015 & -0.187 & 0.077 \\
\hline Age $(y)$ & -0.186 & 0.093 & -0.337 & 0.003 \\
\hline $\mathrm{BMI}\left(\mathrm{kg} / \mathrm{m}^{2}\right)$ & 0.061 & 0.568 & -0.099 & 0.364 \\
\hline Non-smoking vs. current smoking & -0.032 & 0.759 & 0.092 & 0.396 \\
\hline Adjusted $\mathrm{R}^{2}$ & $4.4 \%$ & 0.102 & $8.9 \%$ & 0.020 \\
\hline
\end{tabular}

*Significant genotype $\times$ sex interaction for both cohorts $(P<0.05)$. 
$\mathrm{Val} / \mathrm{Val}$ genotype on ox-LDL-C levels (standardized $\beta$ coefficient $=0.192, P=0.012$ and standardized $\beta$ coefficient $=-0.269, P=0.015$, for middle aged men and oldest old women, respectively). Furthermore, a trend for lower ox- LDL-C levels in old men with the $\mathrm{Val} / \mathrm{Val}$ genotype was also recorded, with a nominal significance (standardized $\beta$ coefficient $=-0.187, P=0.077$ ).

\section{Discussion}

In this study we evaluated the effect of SOD Ala16Val polymorphism on the ox-LDL-C levels in two age-different groups, a middle aged and an oldest old one. The allele frequency recorded in our populations was inversely distributed, comparing to Asians populations (current study: Ala 0.54 and Val 0.46; healthy Chinese: Ala 0.13 and Val 0.87 , healthy Korean: Ala 0.12 and Val: 0.88) (Lee et al., 2006; Mak et al., 2006). On the other hand, the recorded prevalence of the Ala16Val polymorphism in the current study is similar to other Caucasian populations, like Turks (Akyol et al., 2004) and Brazilian residents (Gottlieb et al., 2005).

As oxidative stress is considered to play a critical role in senescence-associated changes, it is conceivable that antioxidant enzymes are important anti-aging agents. Surprisingly, the investigated polymorphism was found to have an inverse effect on ox-LDL-C levels in our two age-different populations. In middle age men, the presence of the Val allele, which according to the literature results to a less active SOD enzyme, was positively associated with ox-LDL-C and HDL-C levels. A possible explanation of the higher HDL-cholesterol levels observed in middle aged men with the $\mathrm{Val} / \mathrm{Val}$ genotype could be a feed-back mechanism in these subjects where the anti-oxidant properties of HDL might compensate the high oxidative stress represented by the elevated ox-LDL levels (Lee et al., 2005). Our finding of increased HDL cholesterol levels in middle-aged subjects with the $\mathrm{Val} / \mathrm{Val}$ genotype is in accordance with the results of other studies (Kakko et al., 2003; Lee et al., 2006), where Val/Val subjects present higher HDL$C$ levels compared to the other genotypes, however without statistical significance. Evidence for the existence of a feed-back mechanism among HDL-C levels and antioxidant enzymes has been demonstrated in subjects with low HDL-C levels (Savor-Blat et al., 2007), as well as in studies with Glutathione peroxidase-1 deficient mice (de Haan et al., 2006). On the other hand, it is well documented, that healthy elderly have higher levels of
HDL-C than younger subjects (Schaefer et al., $1989)$, the vast majority of those over 70 years ( $90.0 \%)$ occurring with HDL-C levels over 40 $\mathrm{mg} / \mathrm{dl}$ (Nikkila and Heikkinen, 1990). This increment in HDL-C levels in healthy oldest old subjects (survivors), also recorded by our previous study (Kanoni et al., 2006), could have overshadowed the potential impact of the SOD genotype.

The opposite was recorded in elderly women, where the Val allele was associated with decreased ox-LDL-C, as well as triglycerides levels. A positive correlation of triglyceride with ox-LDL levels observed in elderly has been previously shown for middle aged people (Lapointe et al., 2007). It is well established that higher TG levels in plasma enhance production of small, dense LDL particles, which are known to be more susceptible to oxidation (Young et al., 2003). Data from the Multi-Ethnic Study of Atherosclerosis (MESA) suggest that, dyslipidemia (adverse levels of cholesterol, HDL-cholesterol, triglycerides), inflammation markers (elevated fibrinogen), male gender, ethnicity (black) and current smoking, could explained the most variation in ox-LDL-C levels, in multivariate analysis model (Holvoet et al., 2006b). The same investigators provide evidence, that ox-LDL-C is a proinflammatory stimulus, inhibiting the expression of the antioxidant SOD1 (Holvoet et al., 2006a). Results (Mocchegiani, 2007) from the large European elderly study (Zincage) suggest that erythrocyte's SOD activity (eSOD) significantly and progressively increase with age, while women exhibit higher eSOD activity compared to men in all age groups. Previously reported results regarding the activity of red blood cell (RBC) SOD, plasma GPX, and, to a lesser extent, plasma SOD are contradictory. Some investigators claim an increase from the youngest to the oldest age groups, which has been correlated with a parallel increase of free radicals (Mecocci et al., 2000; Cheynier, 2005). However, in a cross- sectional study (Andersen et al., 1998) conducted in 41 Danish centenarians and 52 control subjects, Cu/Zn-SOD activity decreased in the centenarians group. In the area of endogenous antioxidant defenses, excess amount of ROS leads to the depletion of the protective GSH and SOD (Kaliora et al., 2006). Very old people represent a highly selected group of successfully aged people. They have apparently escaped the major age-related diseases and exhibit special immunologic or metabolic features (Andersen et al., 1998; Biesalski, 2002). In several studies involving young and elderly groups, some investigators have detected a positive association between age and increased LDL-C oxidation and decreased ox-LDL-C antibodies (Mertens and 
Holvoet, 2001), while others (Nakamura et al., 2006) not. These contradictory results could be attributed to the different population size.

The promoter of MnSOD gene contains binding sites for several transcription factors such as AP-1, AP-2, SP-1, and NF-KB (Harris et al., 1991; Das et al., 1995). In line with this, MnSOD is induced by multiple stress conditions both in vitro and in vivo. MnSOD induction occurs after exposure to cytokines (TNF- $\alpha$, IFN- $\gamma$, IL-1, IL-6) (Ono et al., 1992), cigarette smoke (Gilks et al., 1998), chronic hypoxia (Clerch et al., 1998), asbestos fibers (Janssen et al., 1992), radiation (Guo et al., 2003) and modulators of intracellular redox and/or thiol state (Das et al., 1995). Most of these parameters are age dependent factors and adding smoking as a cofactor in our model, the effect of SOD polymorphism on ox-LDL-C levels remained statistically significant.

Ox-LDL-C appears to be a stimulator of NF- $\mathrm{KB}$ and $A P-1$, which are thought to play a predominant role in endothelial cell activation, resulting in atherogenesis. It has been recently shown (Lin et al., 2007), that overexpression of $\mathrm{Cu}, \mathrm{Zn}-\mathrm{SOD}$ and/or catalase suppress the ox-LDL-induced increase in $\mathrm{AP}-1$ and $\mathrm{NF}-\kappa \mathrm{B}$ activity, providing information on a mechanism potentially explaining the antiatherogenic and antiproliferative activities of antioxidant enzymes. Overexpression of MnSOD inhibits, in vitro, the oxidation of LDL-C by endothelial cells (Fang et al., 1998) and ox-LDL-C is able to induce the expression of MnSOD in macrophages (Kinscherf et al., 1997).

Many SNPs have a significant effect only in the presence of heterozygosity of a second SNP. This type of interaction would not be detected using single-SNP analysis, because SNP genotypes could have a limited effect on a subset of the population, or even antagonistic effects when investigated in combination with a second SNP genotype. These observations are consistent with the hypothesis, that interactions between genetic variants and environmental exposure are the primary causes of phenotypic variability, and not the genetic variants alone (Dedoussis et al., 2007).

An age-dependent effect of a single gene polymorphism was recently shown in a Finish study (Fan et al., 2007). The results suggested that $\mathrm{HL}$ C-480T polymorphism is a strong age-dependent risk factor of sudden cardiac death in middle-aged men. We have no evidence of the underlying mechanism, which could explain the inverse effect of the SOD polymorphism on ox-LD-C levels in the oldest old women. If the decrease in SOD activity, as previously reported, is more evident in the SOD Ala carriers, then this could partially explain the higher ox-LDL-C levels in these subjects. In line with our results and our hypothesis, a recently published study (Taufer et al., 2005), demonstrated that in elderly, the Ala/Ala genotype was associated with increased risk for cancer, immunosenescence profile and DNA damage. The proposed hypothesis for these results by the investigators is based on the free radical theory of aging, concisely suggesting that Ala carriers effectively produce SOD and thus presenting strong innate immunity in their middle-age life, but increased immunosenescence in their latter life. An age related decline in gene expression was recently (Ling et al., 2004) reported for a common Gly482Ser polymorphism in the transcriptional co-activator PGC-1 $\alpha$ in muscle biopsies. Insulin resistance in skeletal muscle increases with age, and since skeletal muscle is a major site of insulin stimulated glucose disposal, aging is a risk factor for type 2 diabetes (Petersen et al., 2003).

The limitations of our study include the crosssectional design, the absence of multiple antioxidant compounds measurements and the evaluation of other genetic markers related to antioxidant enzymes.

Longitudinal studies in both of our populations, as well as the study of other genes known to affect the levels of ox-LDL-C, will add new evidence on the age specific variation in ox-LDL-C levels and the predisposing genetic markers. To our knowledge this is the first report of a dual effect of a polymorphism on ox-LDL-C levels depending on age.

\section{Acknowledgments}

The authors would like to thank the field investigators of "ATTICA" study: Dr. John Skoumas (principal field investigator), Dr. Natasa Katinioti (physical examination), Dr. Spiros Vellas (physical examination), Dr. Efi Tsetsekou (physical/psychological evaluation), as well as the technical team: Dr. Marina Toutouza (senior investigator / biochemical analysis), Mr Manolis Kambaxis (nutritional evaluation), Ms Konstadina Paliou (nutritional evaluation), Ms Chrysoula Tselika (biochemical evaluation), Ms Sia Poulopoulou (biochemical evaluation) and Ms Maria Toutouza (database management). We would also like to thank Mrs Margarita Christea for blood sampling and Dr. Katerina Skenderi for biochemical analysis of the elderly cohort.

\section{References}

Akyol O, Canatan H, Yilmaz HR, Yuce H, Ozyurt H, Sogut S, Gulec M, Elyas H. PCR/RFLP-based cost-effective identification of SOD2 signal (leader) sequence polymorphism (Ala-9Val) using NgoM IV: a detailed methodological approach. Clin Chim Acta 2004;345:151-9 
Andersen HR, Jeune B, Nybo H, Nielsen JB, AndersenRanberg K, Grandjean P. Low activity of superoxide dismutase and high activity of glutathione reductase in erythrocytes from centenarians. Age Ageing 1998;27:643-8

Beyer W, Imlay J, Fridovich I. Superoxide dismutases. Prog Nucleic Acid Res Mol Biol 1991;40:221-53

Biesalski HK. Free radical theory of aging. Curr Opin Clin Nutr Metab Care 2002;5:5-10

Cheynier V. Polyphenols in foods are more complex than often thought. Am J Clin Nutr 2005;81:223S-9S

Clerch LB, Massaro D, Berkovich A. Molecular mechanisms of antioxidant enzyme expression in lung during exposure to and recovery from hyperoxia. Am J Physiol 1998;274:L313-9

Das KC, Lewis-Molock Y, White CW. Thiol modulation of TNF alpha and IL-1 induced MnSOD gene expression and activation of NF-kappa B. Mol Cell Biochem 1995;148:45-57

Dedoussis GV, Kaliora AC, Panagiotakos DB. Genes, diet and type 2 diabetes mellitus: a review. Rev Diabet Stud 2007;4:13-24

de Haan JB, Witting PK, Stefanovic N, Pete J, Daskalakis M, Kola I, Stocker R, Smolich JJ. Lack of the antioxidant glutathione peroxidase-1 does not increase atherosclerosis in C57BL/J6 mice fed a high-fat diet. J Lipid Res 2006; 47:1157-67

El Masry TM, Abou Zahra MA, El Tawil MM, Khalifa RA. Manganese superoxide dismutase alanine to valine polymorphism and risk of neuropathy and nephropathy in egyptian type 1 diabetic patients. Rev Diabet Stud 2005; 2:70-4

Fan YM, Lehtimaki T, Rontu R, Ilveskoski E, Goebeler S, Kajander O, Mikkelsson J, Perola M, Karhunen PJ. Age-dependent association between hepatic lipase gene C-480T polymorphism and the risk of pre-hospital sudden cardiac death: The Helsinki Sudden Death Study. Atherosclerosis 2007;192:421-7

Fang X, Weintraub NL, Rios CD, Chappell DA, Zwacka RM, Engelhardt JF, Oberley LW, Yan T, Heistad DD, Spector AA. Overexpression of human superoxide dismutase inhibits oxidation of low-density lipoprotein by endothelial cells. Circ Res 1998;82:1289-97

Gilks CB, Price K, Wright JL, Churg A. Antioxidant gene expression in rat lung after exposure to cigarette smoke. Am J Pathol 1998;152:269-78

Gottlieb MG, Schwanke CH, Santos AF, Jobim PF, Mussel DP, da Cruz IB. Association among oxidized LDL levels, MnSOD, apolipoprotein E polymorphisms, and cardiovascular risk factors in a south Brazilian region population. Genet Mol Res 2005;4:691-703

Guo G, Yan-Sanders Y, Lyn-Cook BD, Wang T, Tamae D, Ogi J, Khaletskiy A, Li Z, Weydert C, Longmate JA, Huang TT, Spitz DR, Oberley LW, Li JJ. Manganese superoxide dismutase-mediated gene expression in radiation-induced adaptive responses. Mol Cell Biol 2003;23:2362-78

Gutteridge JM, Halliwell B. Free radicals and antioxidants in the year 2000. A historical look to the future. Ann NY Acad Sci 2000;899:136-47
Harman D. Aging: a theory based on free radical and radiation chemistry. J Gerontol 1956;11:298-300

Harris CA, Derbin KS, Hunte-McDonough B, Krauss MR, Chen KT, Smith DM, Epstein LB. Manganese superoxide dismutase is induced by IFN-gamma in multiple cell types. Synergistic induction by IFN-gamma and tumor necrosis factor or IL-1. J Immunol 1991;147:149-54

Holvoet P, Davey PC, De Keyzer D, Doukouré M, Deridder E, Bochaton-Piallat ML, Gabbiani G, Beaufort E, Bishay K, Andrieux N, Benhabilès N, Marguerie G. Oxidized lowdensity lipoprotein correlates positively with toll-like receptor 2 and interferon regulatory factor- 1 and inversely with superoxide dismutase-1 expression: studies in hypercholesterolemic swine and THP-1 cells. Arterioscler Thromb Vasc Biol 2006a;26:1558-65

Holvoet P, Jenny NS, Schreiner PJ, Tracy RP, Jacobs DR. The relationship between oxidized LDL and other cardiovascular risk factors and subclinical CVD in different ethnic groups: The Multi-Ethnic Study of Atherosclerosis (MESA). Atherosclerosis 2007;194:245-52

Janssen YM, Marsh JP, Absher MP, Hemenway D, Vacek PM, Leslie KO, Borm PJ, Mossman BT. Expression of antioxidant enzymes in rat lungs after inhalation of asbestos or silica. J Biol Chem 1992;267:10625-30

Kakko S, Päivänsalo M, Koistinen P, Kesäniemi YA, Kinnula $\mathrm{VL}$, Savolainen MJ. The signal sequence polymorphism of the MnSOD gene is associated with the degree of carotid atherosclerosis. Atherosclerosis 2003;168:147-52

Kaliora AC, Dedoussis GV, Schmidt H. Dietary antioxidants in preventing atherogenesis. Atherosclerosis 2006;187: $1-17$

Kanoni S, Dedoussis G, Manios Y, Malavolta M, Mocchegiani E. Health status, blood and anthropometrical indices from Greek old and nonagenarian subjects. Biogerontology 2006;7:329-37

Kinnula VL, Crapo JD. Superoxide dismutases in malignant cells and human tumors. Free Radic Biol Med 2004; 36:718-44

Kinscherf R, Deigner HP, Usinger C, Pill J, Wagner M, Kamencic H, Hou D, Chen M, Schmiedt W, Schrader M, Kovacs G, Kato K, Metz J. Induction of mitochondrial manganese superoxide dismutase in macrophages by oxidized LDL: its relevance in atherosclerosis of humans and heritable hyperlipidemic rabbits. Faseb J 1997;11:1317-28

Lapointe A, Couillard C, Piche ME, Weisnagel SJ, Bergeron $J$, Nadeau A, Lemieux S. Circulating oxidized LDL is associated with parameters of the metabolic syndrome in postmenopausal women. Atherosclerosis 2007;191:362-8

Lee CM, Chien CT, Chang PY, Hsieh MY, Jui HY, Liau CS, Hsu SM, Lee YT. High-density lipoprotein antagonizes oxidized low-density lipoprotein by suppressing oxygen free-radical formation and preserving nitric oxide bioactivity. Atherosclerosis $2005 ; 183: 251-8$

Lee SJ, Choi MG, Kim DS, Kim TW. Manganese superoxide dismutase gene polymorphism (V16A) is associated with stages of albuminuria in Korean type 2 diabetic patients. 


\section{Metabolism 2006;55:1-7}

Lin SJ, Shyue SK, Shih MC, Chu TH, Chen YH, Ku HH, Chen JW, Tam KB, Chen YL. Superoxide dismutase and catalase inhibit oxidized low-density lipoprotein-induced human aortic smooth muscle cell proliferation: role of cell-cycle regulation, mitogen-activated protein kinases, and transcription factors. Atherosclerosis 2007;190:124-34

Ling C, Poulsen P, Carlsson E, Ridderstrale M, Almgren P, Wojtaszewski J, Beck-Nielsen H, Groop L, Vaag A. Multiple environmental and genetic factors influence skeletal muscle PGC-1alpha and PGC-1beta gene expression in twins. J Clin Invest 2004;114:1518-26

Mak JC, Leung HC, Ho SP, Ko FW, Cheung AH, Ip MS, Chan-Yeung MM. Polymorphisms in manganese superoxide dismutase and catalase genes: functional study in Hong Kong Chinese asthma patients. Clin Exp Allergy 2006;36:440-7

Marklund SL. Human copper-containing superoxide dismutase of high molecular weight. Proc Natl Acad Sci USA 1982;79:7634-8

Masry TM, Abou Zahra MA, El Tawil MM, Khalifa RA. Manganese superoxide dismutase alanine to valine polymorphism and risk of neuropathy and nephropathy in Egyptian type 1 diabetic patients. Rev Diabet Stud 2005; 2:70-4

McCord JM, Fridovich I. Superoxide dismutase. An enzymic function for erythrocuprein (hemocuprein). J Biol Chem 1969;244:6049-55

Mecocci P, Polidori MC, Troiano L, Cherubini A, Cecchetti R, Pini G, Straatman M, Monti D, Stahl W, Sies H, Franceschi C, Senin U. Plasma antioxidants and longevity: a study on healthy centenarians. Free Radic Biol Med 2000;28:1243-8

Mertens A, Holvoet P. Oxidized LDL and HDL: antagonists in atherothrombosis. Faseb J 2001;15:2073-84

Mocchegiani E. Zinc and ageing: third Zincage conference. Immun Ageing 2007;Sep:4-5

Nakamura YK, Read MH, Elias JW, Omaye ST. Oxidation of serum low-density lipoprotein (LDL) and antioxidant status in young and elderly humans. Arch Gerontol Geriatr 2006;42:265-76

Nikkila M, Heikkinen J. High-density lipoprotein cholesterol and longevity. Age Ageing 1990;19:119-24

Ono M, Kohda H, Kawaguchi T, Ohhira M, Sekiya C, Namiki M, Takeyasu A, Taniguchi N. Induction of Mn-superoxide dismutase by tumor necrosis factor, interleukin-1 and interleukin-6 in human hepatoma cells. Biochem Biophys Res Commun 1992;182:1100-7

Petersen KF, Befroy D, Dufour S, Dziura J, Ariyan C, Rothman DL, DiPietro L, Cline GW, Shulman GI. Mitochondrial dysfunction in the elderly: possible role in insulin resistance. Science 2003;300:1140-2

Pitsavos C, Panagiotakos DB, Chrysohoou C, Stefanadis C. Epidemiology of cardiovascular risk factors in Greece: aims, design and baseline characteristics of the ATTICA study.
BMC Public Health 2003;3:32

Povey S, Lovering R, Bruford E, Wright M, Lush M, Wain H. The HUGO Gene Nomenclature Committee (HGNC). Hum Genet 2001;109:678-80

Rosenblat M, Coleman R, Aviram M. Increased macrophage glutathione content reduces cell-mediated oxidation of LDL and atherosclerosis in apolipoprotein E-deficient mice. Atherosclerosis 2002;163:17-28

Rosenblum JS, Gilula NB, Lerner RA. On signal sequence polymorphisms and diseases of distribution. Proc Natl Acad Sci USA 1996;93:4471-3

Sarov-Blat L, Kiss RS, Haidar B, Kavaslar N, Jaye M, Bertiaux M, Steplewski K, Hurle MR, Sprecher D, McPherson $\mathrm{R}$, Marcel YL. Predominance of a proinflammatory phenotype in monocyte-derived macrophages from subjects with low plasma HDL-cholesterol. Arterioscler Thromb Vasc Biol 2007;27:1115-22

Schaefer EJ, Moussa PB, Wilson PW. Plasma lipoproteins in healthy octogenarians: lack of reduced high density lipoprotein cholesterol levels: results from the Framingham Heart Study. Metabolism 1989;38:293-6

Schwenke DC. Aging, menopause, and free radicals. Semin Reprod Endocrinol 1998;16:281-308

Sutton A, Khoury H, Prip-Buus C, Cepanec C, Pessayre D, Degoul F. The Ala16Val genetic dimorphism modulates the import of human manganese superoxide dismutase into rat liver mitochondria. Pharmacogenetics 2003;13:145-57

Taufer M, Peres A, de Andrade VM, de Oliveira G, Sá G, do Canto ME, dos Santos AR, Bauer ME, da Cruz IB. Is the Val16Ala manganese superoxide dismutase polymorphism associated with the aging process? J Gerontol A Biol Sci Med Sci 2005;60:432-8

Tsan MF. Superoxide dismutase and pulmonary oxygen toxicity: lessons from transgenic and knockout mice. Int J Mol Med 2001;7:13-9

Van Remmen H, Williams MD, Guo Z, Estlack L, Yang H, Carlson EJ, Epstein CJ, Huang TT, Richardson A. Knockout mice heterozygous for Sod2 show alterations in cardiac mitochondrial function and apoptosis. Am J Physiol Heart Circ Physiol 2001;281:H1422-32

Wan XS, Devalaraja MN, St Clair DK. Molecular structure and organization of the human manganese superoxide dismutase gene. DNA Cell Biol 1994;13:1127-36

Weisiger RA, Fridovich I. Mitochondrial superoxide simutase. Site of synthesis and intramitochondrial localization. J Biol Chem 1973;248:4793-6

Williams MD, Van Remmen H, Conrad CC, Huang TT, Epstein CJ, Richardson A. Increased oxidative damage is correlated to altered mitochondrial function in heterozygous manganese superoxide dismutase knockout mice. J Biol Chem 1998;273:28510-5

Young IS, McFarlane C, McEneny J. Oxidative modification of triacylglycerol-rich lipoproteins. Biochem Soc Trans 2003;31:1062-5 